mật $(0,087 \pm 0,001 \mathrm{mg})$ so với lô chứng $(0,061 \pm$ $0,002 \mathrm{mg}$ ), làm tăng $41,30 \%$ dịch mật (tính theo khối lượng). Sự khác biệt này có ý nghĩa thống kê $(p<0,05)$.

Như vây sơ bô kết luân cao chiết mâm xôi có tác dụng lợi mật trên mô hình thực nghiệm.

\section{KẾT LUÂN}

Cao chiết mâm xôi có $L D_{50}=\mathrm{g} / \mathrm{kg}$, cao gấp lần liều trên người, chứng tỏ mẫu thử có độ an toàn cao khi sử dung.

Cao chiết mâm xôi ở cả 2 mức liều $0,5 \mathrm{~g} / \mathrm{kg}$ và $1 \mathrm{~g} / \mathrm{kg}$ đều không thể hiện tác dụng chống viêm cấp trên mô hình gây phù bằng carrageenan ở chuột cống.

Cao chiết mâm xôi ở cả 2 mức liều $1 \mathrm{~g} / \mathrm{kg}$ và $2 \mathrm{~g} / \mathrm{kg}$ đều thể hiện tác dụng lợi mật với tỷ lệ lượng dịch mật tăng tương ứng $32,79 \%$ và 41,30\% trên chuột nhắt trắng.

\section{KIẾN NGH!}

Chúng tôi bước đầu đã chứng minh cao chiết cây mâm xôi thu hái tại Thái Nguyên có tác dụng làm tăng tiết mật trên mô hình thực nghiệm và độ an toàn với $L_{50}=12,75 \mathrm{~g} / \mathrm{kg}$. Với mong muốn đưa sản phẩm này vào ứng dung thực tiễn, chúng tôi kiến nghị được tiếp tục nghiển cứu về độc tính bán trường diễn và một số tác dụng bảo vệ gan.

\section{TÀI LIÊU THAM KHẢO}

1. Phạm Hồng Châu (2008), Nghiên cứu thành phần hóa hoc và môt số tác dung sinh hoc của dược liệu mẩm xôi, Khóa luận tốt nghiệm dược sỹ Trường Đai hoc Dước Hà Nôi.

2. Cục khoả học công nghề và đào tạo (2015), Hướng dẩn thử nghiếm tiền lâm sàng và lâm sàng thuốc đông $y$, thuốc từ dược liệu, ban hành kèm theo quyêt định 141/QĐ-K2E்T.

3. Đố Trung Đàm (1996), Phương pháp nghiên cứu độc tính cấp của thuốc, NXB Y học, Hà Nội.

4. Nguyễn Văn Dũng, Trân Ngoc Anh và cs (2019), "Tác dụng điêu chỉnh rối loạn lipid máu trên thực nghiệm của cao chiết cẩy mâm xôi (Rubus alceaefolius Poir, ho Hoa hồng Rosaceae) thu hái tại Thái Nguyên", Tạp chí Y học Việt Nam, 483(2), tr. 178 - 182.

5. Viện Dược liệu (2006), Phương pháp nghiên cứu tác dưng dước lý của thuốc từ thảo dược, NX Khoa hoc và Kỹ thuât.

6. Litfield, Wilcoxon (1948), "A simplified method of evaluating dose-effect experiment", J. Pharmacol Exp. Ther, pp. 99 - 113.

7. Rudi R. V. (1977), Pharm and Toxicology, vol 4 pp. 11-16.

8. Winter C.A., Risley E.A., et al. (1962), "Carrageenan-induced edema in hind paw of the rat as an assay for anti-onflammatory drugs", Proc. Soc. Exp. Biol, 11, pp. 544 - 574.

\title{
ĐẶC ĐIỂM HÌNH THÁI TINH TRÙNG ĐƯợC NHUộM BẰNG PAPANICOLAOU, GIEMSA VÀ EOSIN
}

\section{TÓM TẮT}

Mục tiêu: So sánh đăc điểm hình thái tinh trùng được nhuộm bằng ba phương pháp Papanicolaou, Giemsa, Eosin. Đối tượng và phương pháp nghiên cứu: Mô tả cắt ngang đặc điểm hình thái tinh trùng ở 30 mấu tinh dịch có thông số trong giới hạn bình thường. Mối mấu tinh trùng đươc nhuộm bằng 3 phương pháp Papanicolaou, Giemsa, Eosin. Tiêu bản được quan sát dưới kính hiển vi quang học, hình ảnh được chụp và đo kích thước tinh trùng bằng phần mềm Infinity Analyze. Kết quả: Các đặc điểm chi tiết hình thái bình thường và bất thường của tinh trùng được nhuộm bằng 3 phương pháp không có sự khác biệt có ý nghĩa thông kê. Kích thước đầu tinh trùng nhuộm bằng Eosin lớn hơn so với nhuôm bằng Papanicolaou, Giemsa, sự khác biệt có ý nghĩa thống

*Trường Đại học Y Dược Thái Nguyên

Chịu trách nhiệm chính: Phạm Minh Huệ

Email: phamminhhuebs@gmail.com

Ngày nhận bài: 17/2/2021

Ngày phản biên khoa hoc: 22/3/2021

Ngày duyệt bài: $7 / 4 / 2021$
Phạm Minh Huệ*

kê. Tỷ lệ chiều dài/rônng và đô dài đuôi không khác biệt giữa các phương pháp nhuộm. Phần đâuu và tú cực đâu quan sát rất rõ ở nhuộm Papanicolaou, Giemsa. Phân đuôi và đoạn trung gian quan sát rất rõ ở nhuộm Papanicolaou. Kết luận: Phương pháp nhuôm Papanicolaou phù hợp trong nghiên cứu đánh giá hình thái tinh trùng. Nhuôm Giemsa và Eosin có thể áp dụng trong xét nghiệm tinh dịch đồ thường quy.

Tư khóa: Hình thái tinh trùng, nhuộm tinh trùng, Papanicolaou, Giemsa, Eosin.

\section{SUMMARY}

\section{THE CHARACTER OF SPERM MORPHOLOGY IN PAPANICOLAOU, GIEMSA, AND EOSIN METHODS}

Objectives: Comparison of Morphological sperm stained by Papanicolaou, Giemsa, Eosin methods. Material and methods: A descriptive cross-sectional study of 30 semen samples with normal limited parameters. Each sample stained by Papanicolaou, Giemsa, Eosin methods. The slides were observed under the light microscope, the spermatozoa images were captured and measured in size using Infinity Analyze software. Results: The normal and abnormal 
spermatozoa morphology recorded by the 3 methods had no statistically significant differences. Sperm head size stained by Eosin was larger than sperm head size in Papanicolaou, Giemsa methods. The rate of sperm head length/ width, and length of the tail were not different between the methods. The head and acrosome were very clearly observed in Papanicolaou, Giemsa. The tail and middle piece were very clearly observed in Papanicolaou. Conclusion: Papanicolaou is a suitable method in the study of morphological sperm. Giemsa and Eosin staining can be applied in routine semen testing.

Keywords: Morphological sperm, sperm staining, Papanicolaou, Giemsa, Eosin.

\section{I. ĐĂT VẤN ĐỀ}

Đánh giá chính xác về các thông số của tinh dịch đồ là cần thiết để dự đoán khả năng sinh sản của nam giới, và rất quan trọng trong việc hỗ trợ tối ưu hóa và tối đa hóa khả năng sinh sản trong thụ thai tự nhiên cũng như trong các kỹ thuật hố trợ sinh sản [5]. Trong khi các thông số tinh dịch cơ bản khác như khả năng di chuyển và mật độ tinh trùng quan trọng trong việc dự đoán khả năng sinh sản, thì cấu trúc hình thái tinh trùng dường như là yếu tố quan trong đặc biệt đối kết quả thụ tinh tự nhiên và thụ tinh nhân tạo [2], [8], và liên quan chặt chẽ với kết quả trong kỹ thuật hỗ trợ sinh sản [4].

Nhiêu nghiên cứu đã chứng minh rằng hình dạng đầu tinh trùng bất thường, kết hợp với sự ngưng tụ chất nhiếm sắc bị rối loạn, có thể dẫn đến tinh trùng có đầu dài và hẹp. Trong trường hợp này, việc đánh giá cấu trúc của tinh trùng có tầm quan trọng đặc biệt, vì kích thước và hình dạng của đầu là tiêu chí quan trọng trong việc phân loại tinh trùng đúng về mặt hình thái hoặc xác định những bất thường về hình thái để dự đoán khả năng thụ tinh [7]. Tinh trùng được coi là bình thường nếu hình dạng và kích thước của đầu, giữa và đuôi nằm trong phân loại nhất định theo hướng dẫn của WHO. Điều quan trong là phải lựa chọn kỹ thuật thích hợp để nhuộm tinh dịch [5]. Vì phải quan sát được đây đủ các cấu trúc của tinh trùng (nhân, túi cực đầu, đoạn trung gian, đuôi), quan sát được những chi tiết bất thường xuất hiện (không bào, phần bào tương còn dư'), đồng thời đảm bảo giữ được dạng hình thái chính xác của tinh trùng trong mẫu. Bên cạnh đó, đảm bảo các yếu tố kỹ thuật đơn giản, giá thành rẻ, để phù hợp với các lab nam khoa cơ bản. Vì vậy, chúng tôi tiến hành nghiên cứu với mục tiêu: "So sánh đặc điểm hinh thái tinh trùng được nhuộm bằng ba phương pháp Papanicolaou, Giemsa, Eosin"

\section{II. ĐỐI TƯợNG VÀ PHƯƠNG PHÁP NGHIÊN CứU}

1. Đối tượng nghiên cứu. Nghiên cứu mô tả cắt ngang 30 mẩu tinh tinh dịch được tiến hành xét nghiệm ở nam giới đến xét nghiệm tại Trung tâm CĐTS \&HTSS, Bệnh viện Trường ĐHYD Thái Nguyên.

Tiêu chuân chọn mẫu: 30 mẫu tinh dịch tươi có các thông số trong giới hạn bình thường theo Hướng dẫn của WHO 2010: thể tích $\geq 1,5$ ml; mật độ: $\geq 15.10^{6} / \mathrm{ml}$; độ di động $\geq 40 \%$, hình thái bình thường $\geq 4 \%$

Tiêu chuân loai trứ: mẫu tinh dịch có một hoặc nhiều thông số thấp hơn giới hạn bình thường.

\section{Phương pháp nghiên cứu}

- Mẫu tinh dịch được xuất tinh vào lọ vô khuẩn sau kiêng xuất tinh 3- 5 ngày, được ủ trong tủ ấm $37^{\circ} \mathrm{C}$ trong $30-60$ phút trước khi tiến hành xét nghiệm.

- Mẫu được nhuộm đánh giá hình thái tinh trùng bằng 3 phương pháp nhuộm Papanicolaou, Giemsa, Eosin. Phết 3 lam tiêu bản, để khô tự nhiên $\left(\approx 10^{\prime}\right)$ :

+ Quy trình nhuộm Papanicoloau: Nhúng tiêu bản qua các lọ dung dịch: cồn $96 \%(15 s) \rightarrow 70 \%(15 s) \rightarrow 50 \%(15 s) \rightarrow$ nước cất $(15 s) \rightarrow$ Hematoxylin $\left(6^{\prime}\right) \rightarrow$ Nước cất $(15 s) \rightarrow$ Dung dịch $\mathrm{HCl} 0,5 \%$ trong cồn $(5 \mathrm{~s}) \rightarrow$ Nước cất $(15 \mathrm{~s}) \rightarrow$ Dung dịch Amonicac $1,5 \%$ trong cồn $70 \%(5 s) \rightarrow$ Cồn $50 \%$ (15s) $\rightarrow$ Cồn 70\%(15s) $\rightarrow$ Cồn $96 \%(15 s) \rightarrow$ Thuốc nhuộm OG-6 (2') $\rightarrow$ Cồn $96 \%$ (15s) $\rightarrow$ Cồn $\quad 96 \%(15 s) \rightarrow$ Thuốc nhuộm EA-50 $\left(3^{\prime}\right) \rightarrow$ Cồn $\quad 96 \% \quad$ (15s) $\rightarrow$ Cồn $\quad 96 \%(15 s)$ $\rightarrow$ Xylen(15s) $\rightarrow$ Xylen(15s) $\rightarrow$ Gắn lamel. Tổng thời gian hoàn thành tiêu bản: $>25$ phút.

+ Quy trình nhuộm Giemsa: nhỏ giọt cồn $96 \%$ lên phần đầu của tiêu bản, cho để chảy đều toàn bộ mẫu và chảy dọc về phía đuôi tiêu bản (15s), để khô tự nhiên ( $\approx 5$ phút). Nhỏ dung dịch Giemsa $10 \%$ lền lam, để trong $10^{\prime}$; sau đó rửa dưới vòi nước chảy nhẹ, để khố tự nhiên ( $\approx$ $\left.10^{\prime}\right) \rightarrow$ Gắn lamel. Tổng thời gian hoàn thành tiêu bản: $>30$ phút [1].

+ Quy trình nhuộm Eosin: nhỏ giọt cồn $96 \%$ lên phần đầu của tiêu bản, cho để chảy đều toàn bộ mẫu và chảy dọc về phía đuôi tiêu bản (15s), để khô tự nhiên ( $\approx 5$ phút). Nhỏ dung dịch Eosin lên lam, để trong $5^{\prime}$; sau đó rửa dưới vòi nước chảy nhẹ, để khô tự nhiên $\left(\approx 10^{\prime}\right) \rightarrow$ Gắn lamel. Tổng thời gian hoàn thành tiêu bản: >30 phút.

- Tiêu bản nhuộm được quan sát dưới kính hiển vi quang học Olympus CX31, độ phóng đại $x 1000$. Tinh trùng được quan sát đầy đủ các cấu tạo bao gồm: đâu (và cố) và đuôi (đoạn giữa và đoạn thân). Phân tích 200 tinh trùng mối tiêu bản, nhận diện tinh trùng hình thái bình thường 
và bất thường. Quan sát, chụp hình tinh trùng bằng camera Lumenera Infinity $1-3 C$, và đo kích thước bằng phần mềm Infinity Analyze. Đánh giá khả năng quan sát các thành phần của tinh trùng (đầu, túi cực đầu, đoạn giữa, đuôi) theo thang điểm: 3 (rất rõ) -2 (rõ) -1 (không rõ/không thấy) (đánh giá 200 tinh trùng).

\section{KẾT QUẢ NGHIÊN CỨU}

Bảng 1. Đặc điểm hình thái tinh trùng nhuộm bằng Papanicolaou, Giemsa và Eosin

\begin{tabular}{|c|c|c|c|c|}
\hline Đặc điếm hình thái & Papanicoloau & Giemsa & Eosin & P \\
\hline Bình thường (\%) & $6,3 \pm 1,9$ & $6,1 \pm 1,7$ & $6,0 \pm 1,6$ & \\
\hline Bất thường đâu (\%) & $85,5 \pm 8,8$ & $85,8 \pm 8,1$ & $86,4 \pm 7,2$ \\
\hline Đầu hình quả lề (\%) & $19,1 \pm 10,6$ & $19,2 \pm 10,3$ & $19,2 \pm 9,8$ \\
\hline Đâuu nhọn (\%) & $12,4 \pm 10,0$ & $12,8 \pm 10,0$ & $12,8 \pm 9,8$ \\
\hline Đầu tròn (\%) & $15,6 \pm 11,6$ & $15,8 \pm 11,6$ & $15,7 \pm 11,3$ & \multirow{2}{*}{0,05} \\
\hline Đầu bất định (\%) & $28,9 \pm 12,0$ & $29,1 \pm 11,6$ & $29,2 \pm 11,6$ & \\
\hline Túi cực đầu nhỏ (\%) & $7,47 \pm 6,36$ & $7,67 \pm 6,03$ & $7,76 \pm 6,03$ & \\
\hline Khồng bào (\%) & $2,87 \pm 6,71$ & $2,77 \pm 6,06$ & $2,80 \pm 6,13$ \\
\hline Tế bào chất thừa (\%) & $3,03 \pm 4,78$ & $3,10 \pm 4,61$ & $3,17 \pm 4,60$ \\
\hline Bất thường cố-đuôi (\%) & $44,80 \pm 9,33$ & $45,10 \pm 8,62$ & $45,10 \pm 8,62$ & \\
\hline
\end{tabular}

Nhận xét: Các đặc điếm hình thái bình thường và bất thường của tinh trùng được nhuộm bằng 3 phương pháp không có sự khác biệt có ý nghĩa thông kê

Bảng 2. Kích thước tình trùng hình thái bình thường nhuộm bằng Papanicolaou, Giemsa và Eosin

\begin{tabular}{|c|c|c|c|c|}
\hline Đặc điếm & Papanicoloau & Giemsa & Eosin & P \\
\hline Chiêuu dài đâu $(\mu \mathrm{m})$ & $4,5 \pm 0,3$ & $4,6 \pm 0,2$ & $5,5 \pm 0,6$ & $<0,05^{\mathrm{a}}$ \\
\hline Chiều rộng đầu $(\mu \mathrm{m})$ & $3,1 \pm 0,3$ & $3,0 \pm 0,2$ & $3,4 \pm 0,4$ & $<0,05^{\mathrm{a}}$ \\
\hline Tỷ lề dài/rộng & $1,5 \pm 0,2$ & $1,5 \pm 0,3$ & $1,6 \pm 0,3$ & $>0,05$ \\
\hline Chiều dài đuồi $(\mu \mathrm{m})$ & $46,1 \pm 2,3$ & $45,2 \pm 2,7$ & $46,7 \pm 2,8$ & $>0,05$ \\
\hline
\end{tabular}

*Khác biệt giữa Eosin và Papanicolaou, Giemsa

Nhận xét: Kích thước đâu tinh trùng nhuộm bằng Eosin lớn hơn so với nhuộm bằng Papanicolaou, Giemsa, sự khác biệt có ý nghĩa thống kê. Tỷ lệ chiều dài/rộng và độ dài đuôi không khác biệt giữa các phương pháp nhuộm.

Bảng 3. Điểm đánh giá chất lượing nhuộm tinh trùng bằng Papanicolaou, Giemsa và Eosin

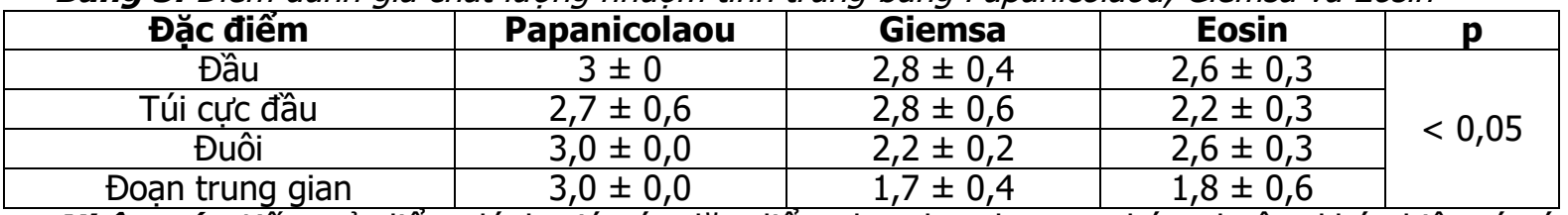

Nhận xét: Kết quả điếm đánh giá các đặc điếm theo ba phương pháp nhuộm khác biệt có ý nghĩa thống kê.
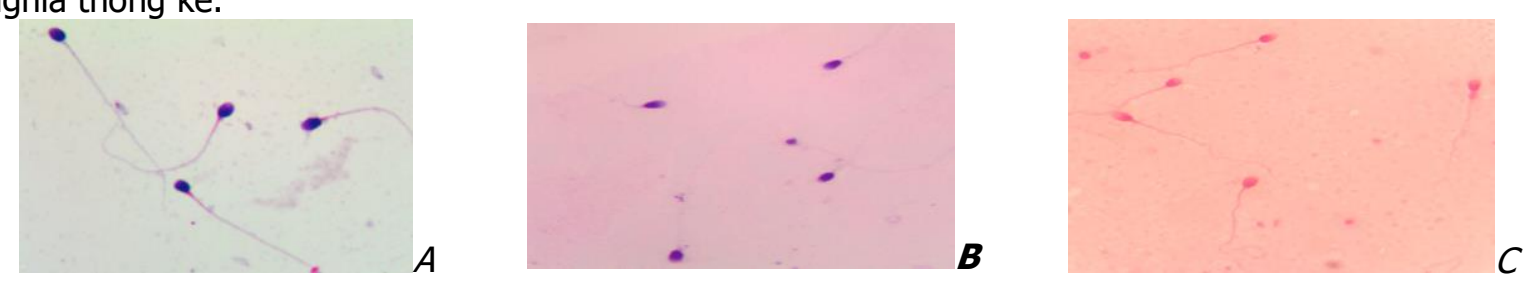

Hình 1. Hinh ảnh tinh trùng nhuộm theo ba phương pháp (X1000):

A. Papanicolaou, B. Giemsa, C. Eosin

Nhân xét: Tinh trùng nhuộm Papanicolaou quan sát được rõ, đẹp và đầy đủ các cấu trúc. Tinh trùng nhuộm Giemsa quan sát được rõ phần đầu, đuôi, tuy nhiên phần đoạn trung gian không xác định rõ. Tinh trùng nhuộm bằng Eosin quan sát được các thành phần, tưy nhiên phần túi cực đầu quan sát không rõ bằng so với nhuộm Papanicolaou và Giemsa.

\section{BÀN LUÂNN}

Để đảm bảo tính khách quan trong đánh giá, lam tiêu bản được ẩn mã số bệnh nhân. Kết quả thu được cho thây các đăc điểm hình thái bình thường và bất thường tinh trùng được quan sát ở 3 phương pháp nhuộm không có sự khác biệt. Với cả phương pháp, có thể quan sát được chi 
tiết các cấu trúc của tinh trùng. Như vậy, với cả phương pháp này có thể áp dụng được trong quan sát hình thái tinh trùng. Chúng tôi tiến hành phần tích định lượng và bán định lượng để đánh giá về chất lượng các mẫu nhuộm, dựa theo một số nghiên cứu khác đã áp dụng [6].

Trong nghiên cứu này, khi nhuộm tinh trùng bằng ba phương pháp, chúng tôi đều quan sát thấy được rõ tinh trùng, với đầy đủ cấu trúc túi cực đầu, nhân, và đuôi; giữ nguyên được hình dáng của tinh trùng trong mẫu. Không quan sát thấy hiện tượng đồng loạt nhiều tinh trùng bị cổ gập, và/ hoặc đuôi bị cuộn lại, do vậy, không làm sai lệch trong đánh giá vì ở tinh trùng bất thường có đặc điểm bất thường cổ, đuôi. Các đăc điểm này có thể xuất hiện bởi kỹ thuật dàn tiêu bản giọt tinh dịch, hoặc bị ảnh hưởng của bởi bước cổ định mấu không tốt. Các yếu tố có thể dẫn đến sai lệch trong đánh giá hình thái tinh trùng này cũng đã được đề cập trong một số báo cáo [3]. Trong nghiên cứu của chúng tôi, kỹ thuật được thực hiện bởi chuyên viên có kinh nghiệm, đồng thời quá trình nhuộm tiêu bản các bước cố định, bước làm khô tiêu bản (ở phương pháp nhuộm Giemsa và Eosin được thực hiện để khô hoàn toàn ở nhiệt độ phòng, không sử dụng nhiệt để làm khô mẫu, vì nếu sử dụng dẫn dến gây teo tế bào tinh trùng).

Eosin là hóa chất được sử dụng trong đánh giá tỷ lệ sống/chết của tinh trùng trong mẫu, tinh trùng chết - màng tế bào không nguyên vẹn, nên Eosin thẩm thấu vào trong tế bào tinh trùng. Trong kỹ thuật đánh giá sống/chết các tác giả lưu ý đối với sử dụng Eosin là dung dịch nhược trương (đặc biệt là sản phẩm thương mại) có thể dẫn đến dương tính giả trong đánh giá sống/chết. Vì vậy, các tác giả nhận định Eosin có thể ảnh hưởng đến chất lượng mẫu nhuộm, dẫn đến bất thường đuôi dương tính giả (đuôi cong, cuộn) do tính nhược trương của Eosin [3]. Với kỹ thuật nhuộm Eosin chúng tôi lưu ý tới bước cố định mẫu và làm khô mẩu tối đa trước khi nhỏ dung dịch nhuộm. Kết quả nghiên cứu mẫu nhuộm bằng Eosin, tinh trùng có kích thước tăng hơn so với mẫu nhuộm bằng phương pháp Papanicolaou và Giemsa, và kích thước tăng hơn so với kích thước trung bình của tinh trùng. Có thể thấy đây là một nhược điểm của Eosin khi nhuộm tinh trùng. Ngoài ra, chúng tôi nhận thây khi để lưu trữ mẩu (đã dán lamel), thì chất lượng hình thái tinh trùng kém hơn so với khi quan sát tiêu bản ngay sau khi nhuộm. Như vậy, mẫu nhuộm bằng Eosin không nên sử dụng trong nghiên cứu, có thể áp dụng trong xét nghiệm tinh dịch thường quy.

Phương pháp Papanicolaou cho kết quả mẫu quan sát được rất rõ các thành phần của tinh trùng. Kỹ thuật này cho phép tinh trùng và các tế bào khác bắt màu tốt với thuốc nhuộm. Với phương pháp nhuộm này, quan sát dưới kính hiển vi quang học, đầu tinh trùng được nhuộm màu xanh tím nhạt ở vùng cực đầu và đậm màu ở phần nhân, đoạn trung gian có màu đỏ và phần đuôi còn lại màu xanh hoặc hơi đỏ. Đối với mẫu nhuộm bằng Giemsa cũng quan sát thấy rất rõ/rõ các thành phần, tuy nhiên một số mẫu có phần đuôi nhìn mờ không rõ (thường gặp ở mẫu có độ nhớt cao). Với mẫu nhuộm Eosin thì quan sát thấy chủ yếu ở mức rõ, phần túi cực đầu một số mẫu quan sát được nhưng không rõ hoàn toàn và đoạn trung gian cũng không xác định được rõ. Trong nghiên cứu của tác giả Lingappa HA và cộng sự (2015), khi đánh giá mẫu nhuộm tinh trùng bằng các phương pháp Haematoxylin \& Eosin, Giemsa, Papanicolau, Eosin- Nigrosin. Kết quả ghi nhận như sau: Túi cực đầu được quan sát thấy rất rõ ở Haematoxylin \& Eosin, Giemsa và Papanicolau; Phần đầu quan sát thấy rất rõ ở Haematoxylin \& Eosin và Papanicolau, thấy được mức độ rõ ở Giemsa và EosinNigrosin; Phần đoạn trung gian chỉ quan sát rõ ở Papanicolau, hai phương pháp còn lại không quan thấy hoặc thấy nhưng không rõ; Phần đuôi quan sát rõ ở Haematoxylin \& Eosin và Papanicolau, với Giemsa và Eosin - Nigosin không quan sát thấy rõ phần đuôi [6].

Phương pháp Papanicolaou có nhiều ưu điểm trong nhuộm tinh trùng, Mặc dù vậy, quy trình này gồm 20 bước liên tiếp với nhiều hóa chất khác nhau. Dẫn đến không chỉ tốn thời gian cho thao tác mà cố định cồn và khử nước bằng cồn hoặc xylen có thế gây co rút tế bào. Hiện nay có hệ thống máy nhuộm tự động, nhưng chi phí khá đắt tiền cho một phòng xét nghiệm nam học căn bản. Ngoài ra, các hóa chất bay hơi sẽ gây độc đến tinh trùng khi thực hiện kỹ thuật lọc rửa cho hỗ trợ sinh sản; và gây ảnh hưởng đển sức khỏe của nhân viên phòng lab, do đó phương pháp nhuộm Papanicoloau cần thực hiện ở một phòng chuyên dụng khác. Như vậy, phương pháp này không thuận tiện trong đánh giá hình thái tinh trùng thường quy; nên sử dụng với các mẫu nghiên cứu vì tiêu bản nhuộm phương pháp này có thể lưu trữ lâu dài không bị giảm chất lượng.

Với hai kỹ thuật nhuộm Giemsa và Eosin, thời gian nhuộm dài hơn không nhiều, các bước nhuộm có khoảng thời gian trống để chuyên viên có thể thao tác đánh giá những thông số khác 
của tinh dịch. Thể tích và loai hóa chất nhuộm cần số lượng ít, giá thành rẻ, ít gây độc hại cho môi trường của phòng lab. Tùy thuộc điều kiện có sẵn của phòng lab có thể dùng Giemsa hoặc Ėosin để đánh giá hình thái tinh trùng, tuy nhiên, Giemsa nên được ưu tiên sử dụng vì thuốc nhuộm này có thể nhuộm rõ hình thái nhân, bào tương các loại tế bào khác có thể xuất hiện trong tinh dich (tế bào tinh trùng chưa trưởng thành, bach cầu, đại thực bào, tế bào biểu mô...), hoặc có thể nhuộm phát hiện được vi khuẩn trong mẫu tinh dịch (nếu có). Giemsa cũng là thuốc nhuộm phổ biến trong ngành Giải phẫu bệnh, Huyết học.

\section{KẾT LUÂ̂N}

Hình thái tinh trùng được nhuộm tốt ở cả ba phương pháp, phương pháp Papanicolaou phù hợp trong nghiên cứu đánh giá hình thái tinh trùng. Nhuộm Giemsa và Eosin có thể áp dụng trong xét nghiệm tinh dịch đồ thường quy.

\section{TÀI LIÊU THAM KHẢO}

1. Bộ Y tế (2016). Hướng dẫn quy trình kỹ thuâat chuyên ngành Giải phẩu bệnh, Tế bào học. Nhà xuất bản Y Học, Hà Nội.

2. Agarwal A, Tvrda $\dot{E}$ and Sharma $R$ (2014) "Relationship amongst teratozoospermia, seminal oxidative stress and male infertility." Reproductive biology and endocrinology : RB\&E. 12: 45-45.

3. Brito LFC, Greene LM, Kelleman A, et al. (2011). "Effect of method and clinician on stallion sperm morphology evaluation." Theriogenology. 76(4): 745-750.

4. Cito G, Picone R, Fucci R, et al. (2020). "Sperm morphology: What implications on the assisted reproductive outcomes?" Andrology. 8(6): 1867-1874.

5. Czubaszek M, Andraszek K, Banaszewska D, et al. (2019). "The effect of the staining technique on morphological and morphometric parameters of boar sperm." PLOS ONE. 14(3): e0214243.

6. Lingappa HA, Govindashetty AM Krishnamurthy A,et al.(2015)."Quest for An Ideal, Simple and Cost-Effective Stain for Morphological Assessment of Sperms." Journal of clinical and diagnostic research: JCDR.9(10): EC01-EC04.

7. Maree L, Du Plessis SS, Menkveld $R$, et al. (2010). "Morphometric dimensions of the human sperm head depend on the staining method used." Human Reproduction. 25(6): 1369-1382.

8. Oehninger $S$ and Kruger TF (2021). "Sperm morphology and its disorders in the context of infertility." F\&S Reviews. 2(1): 75-92.

\section{ĐÁNH GIÁ KẾT QUẢ ĐÎ̀̂U TRI GÃY XƯƠ'NG GÒ MÁ BẰNG NEP VÍT TỰ TIÊU}

\section{TÓM TẮT ${ }^{9}$}

Mục tiêu: Đánh giá kết quả điều trị phẫu thuật gãy xương gò má bằng nẹp vít tự tiêu. Đối tượng và phương pháp: Nghiên cứu mô tả lâm sàng theo dõi dọc. Đối tượng nghiên cứu gồm 20 bênh nhân được chẩn đoán gãy xương gò má theo phân độ III-IV-V của Knight-North. Thời gian từ tháng 01/2019 đến tháng 01/2021. Kết quả: 20 bênh nhân có 11 bệnh nhân nam (55\%), 9 bệnh nhân nữ (45\%). Tuổi trung bình: 24,8. Triêu chứng lâm sàng hay găp: sưng nề, bâm tím quanh mắt $(75 \%)$, đau chói khi sờ $(85 \%)$, mất liên tục bờ dưới ô mắt $(65 \%)$, há miênng han chế $(40 \%)$, tề bì(15\%).XQ: gãy xương gò má di lệch không xoay (35\%), di lệch xoay trong (35\%), di lệch xoay ngoài $(30 \%)$, kết quả sau điều trị về chức năng: tốt $100 \%$; về thẩm mỹ: tốt $(95 \%)$, khá $(5 \%)$. Kết luận: Nẹp vít tự tiêu có thể áp dụng an toàn và hiệu quả cho các trường hợp gãy gò má không phức tạp thay thế cho nẹp vít kim loại.

Tư khóa: Gãy gò má, nẹp tự tiêu

*Bênh viện Hữu nghi Việt Đức

Chịu trách nhiệm chính: Vũ Trung trực

Email: drvutrungtruc@gmail.com

Ngày nhân bài: 18/2/2021

Ngày phản biên khoa hoc: 25/3/2021

Ngày duyệt bài: 8/4/2021
Thịnh Thái*, Bùi Mai Anh*, Vũ Trung Trụ̣c*

\section{SUMMARY}

EVALUATION OF BIORESORBABLE PLATES IN TREATMENT OF ZYGOMACTIC FRACTURE

Objectives: To evaluate the results of surgical treatment zygomatic fracture using bioresorbable plates. Subjects and methods: A clinical description, retrospective study of 20 patients between 01/2019 - 01/2021. Results: We had 20 patients, 11 male patients (55\%), 9 female patients $(45 \%)$. The average age of group: 24,8 . The most common clinical signs: Swelling and bruising (75\%), sharp pain when palpation $(85 \%)$, discontinuity of inferior orbital rim $(65 \%)$, limited mouth opening $(40 \%)$, numbness $(15 \%)$. X ray: displaced body fracture unrotated $(35 \%)$, medially rotated body fracture $(35 \%)$, laterally rotated body fracture $(30 \%)$ The results of treatment: Function: Good (100\%). Esthetic: Good (95\%), Average (5\%). Conclusions: Bioresorbable plates can applied for uncomplicated zygomatic fractues, and bioresorbable osteosynthesiscan be considered a viable alternative to titanium osteosynthesis.

Keywords: Zygomatic frature, bioresorbable plate and screw.

\section{I. ĐĂT VẤN ĐỀ}

Chấn thương hàm mặt nói chung, chấn 